\title{
University-level Soccer Players Adopt a Unique ‘Pacing Strategy’
}

\author{
Ric Lovell ${ }^{1}$ and Matthew Weston ${ }^{2}$ \\ ${ }^{1}$ School of Science \& Health, University of Western Sydney, Australia \\ ${ }^{2}$ Department of Sport \& Exercise Sciences, School of Social Sciences \& Law, \\ Teesside University, Middlesbrough, UK
}

\section{Dear Editors,}

We were interested to read the recent article by Mugglestone et al. [9], which examined high-speed running performances of University soccer players during the early stages of each half in competitive match-play. The data is a welcome addition to a small body of work examining the within-match trends in soccer work rate, with particular reference to the half-time interval and its impact upon players' subsequent physical performances. In this letter we direct the authors to several relevant studies that were not considered in their article $[1,3,11,12]$. We hope that by highlighting these research contributions to the authors and readership, interpretation of withinmatch analysis trends can be undertaken with necessary due care and caution.

The authors' main observations were no differences in high-speed running parameters between the corresponding periods at the start of each half (5- and 15min periods). This observation is in direct contrast with previous time-motion analysis studies $[1,3,7,11,12]$. Mugglestone and colleagues [9] reconciled that the method of time-motion analysis may in-part explain this discrepancy. However, this is unlikely as previous studies reporting between-half differences utilised a wide-range of techniques, including video-analysis [7], semi-automated image tracking [1,11,12], and global positioning systems [3]. Player standard, acute preparation routines, pacing strategies, or methodological concerns of $1 \mathrm{~Hz}$ GPS systems might contribute to the exclusive nature of the authors' data. Notwithstanding, we urge researchers and practitioners to interpret between-half contrasts of this nature carefully as the validity of using the opening phase of the match as a criterion for comparisons is questionable given its intense and frantic nature [3]. Furthermore, passive half-time intervals cannot be assumed in time-motion analysis studies, given the increasing trend for rewarming activities during this period [10].

On a practical level, the absence of reduced physical performances at the start of the second half led to the authors questioning the value of half-time re-warm-up strategies that have been recommended $[4,5,8,13]$ and translated into practice [10]. We feel that such a strong assertion made from this data set is unwarranted. The objective of a half-time re-warm-up is not simply to enhance the work-rate of a player, rather to optimise their capacity to undertake high-intensity actions, and to be more resistant to injury during the early stages of the second half. With this in mind we would like to take this opportunity to direct the authors to recent evidence in controlled laboratory settings, demonstrating performance improvements and reduced injury risk with re-warming strategies suitable for applied settings $[4,13]$. Although players and their coaches often lack motivation to perform a re-warm-up at half-time, practitioners have identified a 3-minute window of opportunity [10], and preliminary data suggests that such activities are not detrimental to physical performances at the end of the match [4].

Mugglestone and colleagues [9] conclude that the absence of between-half differences might be indicative of a distinct pacing strategy. Unfortunately the 
authors do not elaborate on this resolution. Yet it is an attractive hypothesis and merits further exploration. Based on the time-motion analysis data reported in the paper, we agree that pacing phenomena might explain the discrepancy between University players with professional [1,11,12] and youth players [3]. For example, the amplitude of temporary work-rate fluctuations during match-play are seemingly greater in higher standard professional players when compared to lower ranked and also elite youth players $[1,2,7,8]$. Overall, the work-rate of an elite, professional soccer match depicts a positive pacing strategy during each half [12], whereby the proportion of HSR performed in the first 15-min of each half is often the greatest $[1,7,12]$. However, the University players covered only $16 \%$ of the total half highspeed running in the opening 15-min periods of each half, implying a negative pacing strategy. To our knowledge this is an unprecedented trend in soccer. Might this explain the unique observation that HSR parameters were not reduced after a passive half-time interval? We would encourage the authors to re-examine their within-match work rate trends in more detail and encourage further dialogue and research on this topic.

\section{References}

1. Bradley PS, Sheldon W, Wooster B, Olsen P, Boanas P, Krustrup P. Highintensity running in English FA Premier League soccer matches. J Sports Sci 2009: 27, 159-168.

2. Lovell R, Barrett $S, A b t \mathrm{G}$. 'Temporary fatigue' is not apparent in elite youth soccer players. In Nunome H, Drust B, Dawson B (eds). Science and Football VII: Proceedings of the Seventh World Congress on Science and Football. London: Routledge, 2013b: 139-145.

3. Lovell R, Barrett S, Portas M, Weston M. Re-examination of the post half-time reduction in soccer work-rate. J Sci Med Sport 2012: 16(3), 250-254.

4. Lovell R, Midgley AW, Barrett S, Carter D, Small K. Effects of different halftime strategies on second half soccer-specific speed, power and dynamic strength. Scand J Med Sci Sport 2013a: 23(1), 105-113.

5. Lovell RJ, Siegler JC, Kirke I, McNaughton LM, Greig MP. Soccer half-time strategy influences thermoregulation and endurance performance. J Sports Med Phys Fit 2007: 47, 263-269.

6. Mohr M, Krustrup P, Andersson H, Kirkendal D, Bangsbo, J. Match activities of elite women soccer players at different performance levels. J Strength Cond Res 2008: 22, 341-349.

7. Mohr M, Krustrup P, Bangsbo J. Match performance of high-standard soccer players with special reference to development of fatigue. J Sports Sci 2003: 21, 439-449.

8. Mohr M, Krustrup P, Nybo L, Nielsen JJ, Bangsbo J. Muscle temperature and sprint performance during soccer matches - beneficial effect of re-warm-up at half-time. Scand J Med Sci Sports 2004: 14, 156-162.

9. Mugglestone C, Morris JG, Saunders B, Sunderland C. Half-time and highspeed running in the second half of soccer. Int J Sports Med 2013: 34(6), 514-519.

10. Towlson C, Midgley AW, Lovell R. Warm-up strategies of professional soccer players: Practitioners' perspectives. J Sport Sci: DOI: 10.1080/02640414.2013.792946 [Epub ahead of print].

11. Weston M, Batterham A, Castagna C, Portas M, Harley J, Barnes C, Lovell R. Reduction in physical match performance at the start of the second half in elite soccer referees and players. Int J Sports Phys Perf 2011a: 6(2), 174182.

12. Weston M, Drust B, Gregson W. Intensities of exercise during match-play in FA Premier League referees and players. J Sports Sci 2011b: 29, 527-32. 
13. Zois J, Bishop D, Fairweather I, Ball K, Aughey RJ. High-intensity re-warmups enhance soccer performance. Int J Sports Med 2013: DOI: 10.1055/s0032-1331197 [Epub ahead of print].

\section{Contact Details for the Corresponding Author:}

Dr Ric Lovell

School of Science \& Health, University of Western Sydney, Locked Bag 1797,

Penrith South DC, 2751, New South Wales,

AUSTRALIA.

Email: r.lovell@uws.edu.au

Ph: $0061(0) 246203304$

Fax: $0061(0) 246203792$ 